Revista Iberoamericana. Vol. LXIV, Núms. 184-185, Julio-Diciembre 1998; 507-528

\title{
DE VIAJEROS Y TURISTAS: REFLEXIONES SOBRE EL TURISMO EN LA LITERATURA HISPANOAMERICANA
}

\author{
POR \\ CRISTÓBAl Pera \\ Universidad de Barcelona
}

Una reflexión sobre el desplazamiento ${ }^{1}$ en la literatura hispanoamericana exige el análisis documentado de las huellas que comienza a dejar el fenómeno sociológico del turismo en textos de finales del siglo XIX y principios del XX. Consiguientemente requiere poner en evidencia cómo el paso del "aristocratismo" del viajero a la "democratización", que impone la llegada del turista, puede considerarse como un signo característico de la modernidad que provoca en los escritores hispanoamericanos ambivalentes reacciones y reflexiones, desde el rechazo hasta la asimilación, y cuyos ecos llegan hasta nuestros días.

Si pensamos en la relevancia del viaje en la literatura hispanoamericana debemos remontarnos a los orígenes y admitir que una gran parte de la producción textual durante la conquista y la colonia está compuesta por narraciones de viaje; un viaje en el que el protagonista forma parte de la expedición colonizadora y en el que se confronta con el Otro y consigo mismo. ${ }^{2}$ En las postrimerías del período colonial, durante la Ilustración, el viaje de conquista y colonización ha sido sustituído por viajes exploratorios y científicos cuyos protagonistas siguen siendo europeos ligados a nuevas iniciativas expansionistas. Esta nueva oleada de viajeros europeos, cuyo máximo exponente es Alexander Von Humbolt,

\footnotetext{
' En el reciente y fundamental estudio de Caren Kaplan, Questions of Travel: Postmodern Discourses of Displacement, la autora demuestra de qué modo las metáforas relativas al viaje y al desplazamiento influyen poderosamente en las representaciones culturales, especialmente en la teoría literaria. En su estudio, Kaplan llama la atención acerca de las continuidades y discontinuidades entre términos como "viaje", "desplazamiento", así como entre las prácticas específicas e identidades que definen "exilio", "turista" y "nómada" (2). Advirtiendo de la diferencia entre ambos términos, Kaplan utliliza precisamente el término "desplazamiento" (relacionado preferentemente con la inmigración) y lo yuxtapone a "viaje" (relacionado preferentemente con el ocio y el privilegio), para poner en evidencia las construcciones de ciertas prácticas críticas y estéticas que crean el mito del exilado en la modernidad y desestabilizar los modernos mitos referentes al viaje y la creación literaria (5).

${ }^{2}$ Me parece muy sugestiva y apropiada para el propósito de este artículo la idea de Todorov en The Conquest of America, de que precisamente el viaje, y por lo tanto el Diario de Colón-el primer texto sobre América escrito por un occidental - tienen su origen precisamente en un libro de viajes, en los Viajes de Marco Polo: "This discovery (the lands) seems in truth subject to a goal, which is the narrative of the voyage: one might say that Columbus has undertaken it all in order to be able to tell unheard-of stories, like Ulysses; but is not a travel narrative itself the point of departure, and not only the point of arrival, of a new voyage? Did not Columbus himself set sail because he had read Marco Polo's narrative?" (13).
} 
inicia un proceso de reinvención y redefinición de Hispanoamérica que coincidirá con los inicios de su independencia de España. ${ }^{3}$ Tal proceso de reinvención no solo afecta a las élites europeas, sino especialmente a la visión de los intelectuales americanos que debían enfrentarse con una nueva era republicana, seleccionando y adaptando las perspectivas europeas en su afán de crear valores de descolonización (Pratt 112). Es interesante notar cómo uno de los primeros textos en que se produce esa reinterpretación de la realidad americana toma la forma de un manual para viajeros. Se trata de El lazarillo de ciegos caminantes (1773), de Alonso Carrió de la Vandera, verdadero antecedente de las guías turísticas, al que críticos como José Miguel Oviedo han llegado a calificar como Baedecker americano. ${ }^{4}$ Es a partir de finales del XVIII cuando la corriente de viajeros comienza a invertir su sentido, cuando son los ciudadanos de las nuevas repúblicas quienes se desplazan a Europa, utilizando en su exploración estrategias textuales similares a las empleadas por los viajeros europeos que visitaban sus tierras. Las Memorias de Fray Servando Teresa de Mier ${ }^{5}$ podrían considerarse como uno de los textos de viajes que inauguran ese proceso de reinvención de Europa, y de los cuales son herederos Sarmiento y la generación argentina del ochenta. Será entonces cuando se plantee la cuestión de la autoridad discursiva del viaje vivido por un escritor hispanoamericano y de su estatus como viajero.

Pero ya desde la primera mitad del siglo XIX aparece una nueva figura en el espectro sociológico que va a enfrentarse con la figura del viajero: es el turista, producto de una industria que comienza a desarrollarse en el mundo anglosajón. Entre los años 1820 y 1850 , con la expansión y consolidación de los nuevos medios de transporte, aparecen una serie de instituciones que, directa o indirectamente, permiten el turismo o lo facilitan expresamente.

${ }^{3}$ En Imperial Eyes: Travel Writing and Transculturation, Mary Louise Pratt expone cómo la producción textual de los libros de viajes reinventa los territorios colonizados para los lectores europeos sirviendo como un instrumento más de las ansias expansionistas y de qué manera tales modos de representación son recibidos y apropiados por los grupos de la periferia. Con respecto a Hispanoamérica, Pratt afirma: The reinvention of América, then, was a transatlantic process that engaged the energies and imaginations of intellectuals and broad reading publics in both hemispheres, but not necessarily in the same ways. For the elites of Northern Europe, the reinvention is bound up with possibilities for European capital, technology, commodities, and systems of knowledge. The newly independent elites of Spanish America, on the othe hand, faced the necessity for self-invention in relation both to Europe and the non-European masses they sought to govern. One can only be fascinated, then, that the writings of Alexander von Humbolt provided founding visions to both groups (112).

${ }^{4}$ José Miguel Oviedo, en su Historia de la literatura hispanoamericana: 1 . De los origenes a la Emancipación, titula el capítulo dedicado a Carrió de la Vandera "Un Baedecker americano: 'El lazarillo' de Carrió de la Vandera", y escribe al respecto: "Es, en esencia, un Baedecker sobre una popular ruta americana, con la advertencia de que esta guía antecede por casi 50 años a la primera que publicó Baedecker en Alemania (1828)" (320).

${ }^{5}$ Kathleen Ross, en "A Natural History of the Old World: the Memorias of Fray Servando Teresa de Mier”, examina las memorias del mexicano Fray Servando Teresa de Mier, quien viaja al viejo mundo a principios del siglo XIX y describe críticamente algunos países europeos por los que viaja. Ross señala el paralelismo retórico entre esta descripción del Viejo Mundo y el modo en que se describía el Nuevo Mundo en las crónicas, como un modo de subversión de los modelos establecidos por las crónicas de Indias. En el caso de Sarmiento no están presentes las crónicas como modelo, sino los libros de viajes de exploradores y científicos europeos como Von Humbolt. 
Con la consolidación de estas instituciones (Murray, Baedecker, Cook), el turista pasa a ser considerado e identificado como $s u$ criatura, como el producto y el cliente de estructuras comerciales que administran el viaje de ocio de acuerdo con las exigencias de las empresas comerciales y su burocracia. Como consecuencia, el estatus privilegiado del viajero es redefinido en oposición a estas instituciones dedicadas al turismo. A partir de entonces, como se verá enseguida, una de las características típicas de la narrativa de viajes consistirá en el evidente esfuerzo del autor por distanciarse de esa nueva estructura organizada que trae el turismo, en una demostración consciente de independencia frente a la figura del turista (Buzard 47).

Ya David Viñas, en "El viaje a Europa", estudió en profundidad los diferentes talantes con que, desde finales del siglo XVIII, los escritores argentinos confrontan su condición de viajeros al Viejo Continente. ${ }^{6}$ En primer lugar distingue el "viaje colonial", cuyo texto canónico es la Autobiografia de Belgrano quien, según Viñas, viaja a Europa y se sitúa ante lo europeo y en especial frente a lo español en una relación de súbdito a corte:

Belgrano, a finales de ese siglo (XVIII) se muestra como sujeto pasivo del viaje: mi padre 'me mandó, 'se apoderaron de mí las ideas', 'me colocaron en la secretaría del Consulado', 'se apoderó de mí el deseo'[...] que subraya la correlación corte-súbdito y la pasividad de Belgrano en esa coyuntura (140).

Tras la independencia, Viñas considera el "viaje utilitario", encarnado en Alberdi y en el que la relación súbdito-corte es superada y pasa a ser un "espectador americano" que erige su juventud en privilegio romántico y al que Europa, en tanto un gran aprendizaje, se le convierte en la universidad, la academia y el pensamiento sistemático (144). Como afirma Viñas, "la antigua relación colonial se ha invertido aunque a otro nivel: la pasividad ha sido reemplazada por la iniciativa, pero lo reverencial no se disuelve" (146). El afán de apropiación que revelan los textos de viajes es resaltado por Viñas: "a Europa se 'la posee' pero mediante estadísticas[...] Alberdi es una avanzada sobre Europa y su estilo se limita a consignar datos útiles" (148). Es en Sarmiento en quien Viñas encuentra una nueva actitud que califica como "viaje balzaquiano". El intelectual americano de viaje ya no se conforma con servir de soporte como público al escritor europeo sino que pretende conquistar la ciudad: "con Sarmiento la mirada sobre Europa ya no es tanto de reverencia, como de ganas; no de contemplación platónica, sino de posesión" (161).

Sarmiento asume el papel de viajero en su obra Viajes por Europa, Africa y América: 1845-1847, editado en Santiago de Chile, en 1849. Pero en Sarmiento encontramos cómo el viaje a Europa provoca en él una reflexión sobre su identidad como hispanoamericano que en autores como Mansilla queda sepultada por su afán mimético con el paisaje que encuentra y por las anécdotas. Si a lo largo del siglo XIX cientos de viajeros y científicos europeos

\footnotetext{
${ }^{6}$ Véase también al respecto el artículo de George D. Schade, "Los viajeros argentinos del ochenta", en donde examina los libros de viajes de autores argentinos de la segunda mitad del siglo XIX. Entre ellos destaca: Viajes a Europa, Africa y America (1849) de Domingo F. Sarmiento, De Aden a Suez (1855) de Lucio Mansilla, Recuerdos de viaje (1880) de Lucio V. López, Impresiones (1884) de Martín García Mérou, Del Plata al Niagara (1884) de Paul Groussac, En viaje (1884) de Miguel Cané y Viajes y observaciones (1892) y Por mares y por tierras (1899) de Eduardo Wilde.
} 
organizan expediciones científicas para, en muchos casos, indagar acerca del origen del hombre y de la historia en el subcontinente americano, Sarmiento emprende el mismo viaje pero en sentido contrario. Su exploración tendrá, tal vez, como íntimo objetivo el encuentro con ese origen, tanto nacional como personal, pero el resultado será el hallazgo de algo ya presentido y conocido desde la distancia: la modernidad. ${ }^{7}$ Como afirma James Buzard en su libro sobre las relaciones entre turismo y literatura en el mundo anglosajón, The Beaten Track: European Tourism, Literature, and the Ways to Culture. 1800-1918:

the intellectual currents of Romanticism played an important part in shaping the development of tourism, both in England and abroad. Tourism quickly became embroiled in the issue of how modernity itself might be characterized and confronted (19).

A pesar de que el papel de Sarmiento es todavía el de viajero, y de la ausencia de cualquier referencia al turista, la búsqueda y confrontación con la modernidad será un objetivo prioritario de su viaje.

Desde mitad del siglo XIX comienza a aparecer la figura del turista europeo en las ciudades de Hispanoamérica. Un viajero francés pasea por las calles del Buenos Aires rosista de 1850 y, como conocedor de ese "París real" de donde procede, descubre con decepción los claros signos de la mímesis que se está produciendo en las ciudades de Hispanoamérica.

Para ayudarme a exponer algunas de estas imágenes cotidianas, suponga el lector que me acompaña por algunos momentos en un paseo a pie por las calles de la ciudad. Entramos en la calle de Perú: a derecha e izquierda se descubre el lujo y la industria de Francia: en las mueblerías, joyerías y peluquerías; en las sedas recién llegadas de Lyon y en las cintas de Saint-Etienne, así como en las últimas creaciones en vestidos y sombreros. Detrás de una ventana enrejada, una muchacha prepara una guirnalda de flores artificiales que podría figurar muy bien en un salón del Quartier Saint-Germain; un sastre coloca en su vidriera el nuevo figurín del Journal des Modes que ha llegado la víspera por el paquebote del Havre y que será la atracción de los elegantes (citado en Romero 228).

El viajero europeo no hace sino constatar una tendencia que siguen muchas capitales hispanoamericanas desde mitad del siglo XIX al tratar de transformarse a imagen y semejanza de ciudades como París. Y es eso justamente lo que el viajero francés anteriormente citado, ya con la mentalidad del turista, no quiere encontrar. Como afirma Buzard,

Britons and Americans agreed that Italy possesed the greatest concentration of the valuably different in Europe, the greatest density of Europeanness, as long as that nation seemed exempt from modernity, untouched by industry, nationalism, political democracy, and secularism [...] as an entrance into the inner sanctorum of European otherness (32).

\footnotetext{
${ }^{7}$ Con respecto a la visión de Europa que despliega Sarmiento enViajes, véase el capítulo "Reinventing América/Reinventing Erurope: Creole self-fashioning" en Mary Louise Pratt, op. cit., 172-297, y Cristóbal Pera, "Una incursión en la modernidad: Sarmiento en París", Modernistas en Paris: el mito de Paris en la prosa modernista hispanoamericana (43-68).
} 
De igual modo podría decirse que ese encuentro con naciones "exentas de la modernidad" es lo que, en mi opinión, caracteriza el viaje del europeo por Hispanoamérica.

Los motivos de un viajero hispanoamericano como Sarmiento por Europa se deberán a razones diametralmente opuestas a las del viajero británico o norteamericano que va a Italia. El viaje de Sarmiento a Europa tiene, para empezar, un objetivo didáctico: el estudio, por encargo del gobierno chileno, de la educación primaria en las naciones adelantadas y los problemas de orden inmigratorio y colonizador. ¿Cómo expresar la singularidad del viaje vivido por el hispanoamericano a Europa? ¿Cómo trasponer la estructura de una sociedad "más adelantada", percibida a través del "ojo miope" de un representante de las sociedades "'menos adelantadas"? Esta es la cuestión que se plantea Sarmiento.

Mayor se hace todavía la dificultad de escribir sobre viajes, si el viajero sale de las sociedades menos adelantadas, para darse cuenta de otras que lo son más. Entonces se siente la incapacidad de observar, por falta de la necesaria preparación del espíritu, que deja turbio y miope el ojo, a causa de lo dilatado de las vistas, y la multiplicidad de los objetos que en ella se encierran (Viajes: De Valparaiso a París 28).

Al rechazar los modelos de viaje entonces vigentes, el "viaje escrito" y las "impresiones de viaje", Sarmiento elige la forma epistolar y así insiste sobre esta soledad expresiva del escritor americano. Como afirma Roberto Hozven,

Frente al celo mimético del uno y la invención edénica del otro, el escritor americano (consumidor de modelos él mismo privado de modelos) queda supeditado al vigor autonímico con que se atreve a fundar la validez de su propio discurso: "He escrito, pues, lo que he escrito, porque no sabría como clasificarlo de otro modo". Viajero protagónico de su propio desamparo interpretativo, DFS hace del acto de escribir el efecto de su propia causa, no hay otro modelo que funda su discurso que el que le proporciona su propio acto de interlocución, de escritura (438).

La evolución del viajero decimonónico al turista de fin de siglo provocará en los modernistas hispanoamericanos una reacción contra el turismo y los turistas, la búsqueda de una "experiencia cultural auténtica" frente a la "experiencia turística", y la difusión de un turismo "textual" a través de las crónicas periodísticas, cuyo modelo estará sacado en ocasiones de las guías turísticas, de los "Baedecker". ${ }^{8}$ En este sentido, creo que la aparición del fenómeno del turismo será determinante en esa pérdida de autoridad discursiva que anunciaban las palabras de Sarmiento. El trabajo de Ali Behdad, Belated Travelers: Orientalism in the Age of Colonial Dissolution, puede proporcionarnos algunas claves al respecto cuando expone el desplazamiento discursivo que se produce en la literatura de viajes orientalista desde las narraciones de estos viajes a las guías turísticas. Behdad detecta

\footnotetext{
${ }^{8}$ Acerca del viaje en el modernismo véase Karima Hajjaj, “Crónica y viaje en el Modernismo: Enrique Gómez Carrillo y 'El encanto de Buenos Aires"”; Luis Sáinz de Medrano, "Los viajes de Rubén Darío por Hispanoamérica"; Mihai Grünfeld, "De viaje con los modernistas" y Cristóbal Pera, "Modernistas en París: el mito de París en la prosa modernista hispanoamericana". Existe una tesis doctoral, que no he podido consultar, dedicada específicamente al tema: Jacinto Rafael Fombona Iribarren, El texto de viajes modernista: Viajeros hispanoamericanos y la construcción de Europa.
} 
en escritores como Gerard de Nerval las primeras referencias a ese nuevo personaje con el que comienzan a toparse los viajeros.

\begin{abstract}
Nerval's nostalgia for a time when "real" adventures in unknown lands were possible and his derogatory use of the word touriste - which appeared in the French language ony in 1816 - can be taken as signals of genealogical discontinuity in the identity of the orientalist. They announce the gradual disappearance of the adventurous traveler who undertook the troublesome journey in search of new "knowledge", romantic encounters, and exotic experiences (35).
\end{abstract}

Un ejemplo sobresaliente del escritor que comienza a asumir la modernidad del fenómeno del turismo es el guatemalteco Gómez Carrillo, quien representa la imagen del escritor modernista como turista en oposición a la imagen del escritor como explorador o viajero que presentaba Sarmiento. La mediación de los libros de viaje de científicos europeos que se podía apreciar en escritores como Sarmiento será sustituida, en cierta medida, por la mediación del comercio y de las guías turísticas en escritores como Darío y Gómez Carrillo. Remedando el título del libro de Behdad, los modernistas hispanoamericanos podrían contemplarse como "viajeros tardíos". Acuciados por el turismo que había convertido lo "exótico" y "pintoresco" en "familiar", modernistas como Darío o Gómez Carrillo experimentan la sensación de ser "viajeros tardíos", de haberse perdido la "experiencia auténtica" que antes ofrecía un mundo que ahora desaparecía. Y el desplazamiento discursivo al que se refiere Behdad encuentra su vehículo ideal en la crónica modernista y en el "deseo" de los lectores. Si sustituimos el Oriente por Europa (o literalmente en el caso de libros de viajes por Oriente como los de Gómez Carrillo), la reflexión de Behdad puede aplicarse a ese desplazamiento de la autoridad discursiva que propicia el turismo:

Tailored to the needs of amateur travelers in search of leisurely vacations in the Orient, the discourse of tourism[...] does not derive its authority from the interpretive power of a centralized subject of enunciation - the meaning-making "I" of the travelogue - but depends for its discursive economy on the possible positions of desire occupied by its readers (16).

Ciertos cronistas y escritores como Darío y Gómez Carrillo, se presentan como depositarios del "secreto" de ciudades como París y adoptan el papel de guías turísticos textuales, convirtiendo algunas de sus crónicas en auténticas guías de viaje para sus lectores. Las Exposiciones Universales serán el lugar en donde estos escritores se darán de bruces con el fenómeno del turismo a gran escala. Si se tiene en cuenta que la Exposición Universal de 1889 recibió la increíble cifra de 32 millones de visitantes, ${ }^{9}$ gran parte de ellos llegados gracias a la industria turística organizada, es comprensible el distanciamiento que estos escritores tratan de crear entre su figura y la del turista.

${ }^{9}$ Daniel Canogar, en Ciudades efimeras: Exposiciones universales; espectáculo y tecnología, presenta en un anexo las cifras de visitantes de todas las Exposiciones Universales realizadas hasta la fecha (122). 
A partir de este momento conviene resaltar la importancia que las Exposiciones Universales van a tener en el desarrollo del turismo como industria. Uno de los primeros grandes éxitos de esta industria fue obra de Thomas Cook, quien en 1855 logró traer 165.000 visitantes al Palacio de Cristal de la $1^{\text {a }}$ Exposición Universal de Londres. Para las nuevas repúblicas iberoamericanas, las Exposiciones Universales aparecen como el mejor medio de darse a conocer al mundo, de ser reconocidas, inter pares, en un mismo recinto físico. Es por tal razón por la que muchas de ellas se decidieron a presentarse a las Exposiciones Universales que, desde mitad de siglo, se celebran en París. No sólo es una oportunidad para reforzar la identidad nacional sino también una ocasión que aprovecha la prensa para enviar a sus primeros corresponsales, que traerán de allí una imagen reforzada de París como centro del mundo, como la cosmópolis que dirige el concierto de las naciones. Y allí irán a parar entre otros, Martí, Darío y Gómez Carrillo.

Una de las primeras muestras de ese enfrentamiento que comienza a producirse entre la figura del viajero y la del turista puede apreciarse en la crónica que le dedica Darío a la Exposición de 1900 en su libro de crónicas titulado Peregrinaciones (1901). Para empezar, Darío es consciente de la importancia de las guías turísticas, y lo primero que hace es asomarse a la ciudad desde lo alto de la torre Eiffel.

Visto el magnífico espectáculo como lo vería un águila, es decir, desde las alturas de la torre Eiffel, aparece la ciudad fabulosa de manera que cuesta convencerse de que no se asiste a la realización de un ensueño. La mirada se fatiga; pero aún más el espíritu ante la perspectiva abrumadora, monumental (380).

A pesar de su intento de distanciarse de la perspectiva del turista, al subir a la torre Eiffel y contemplar el panorama "monumental" de París, Darío está siguiendo los primeros pasos recomendados a los turistas por la más famosa guía para turistas de habla inglesa: The Anglo-American Guide to Exhibition Paris, 1900, cuando aconsejaba a sus lectores que, antes de visitar la Exposición, suban a la torre Eiffel: "The Exhibition with its marvellous palaces and pavillions, its gardens and terraces, is seen to the greatest advantage, and produces an effect of confused architectural magnificence never to be forgotten[...]" (357). Sin duda Darío no lo olvidó pues, al igual que el autor de la guía, lo primero que señala al mirar la ciudad desde arriba es "la agrupación de todas las arquitecturas, la profusión de todos los estilos, de la habitación y del movimiento humano"(380).

Como ya ha sido mencionado, ciertos cronistas y escritores, entre ellos Darío y Gómez Carrillo, se presentarán como depositarios del secreto de una ciudad como París, en una actitud elitista que, en mi opinión, tiene su origen en esa reacción frente al desarrollo del turismo de masas que comienza a finales del sigloXIX. Tal hecho explicaría el distanciamiento que Darío trata de crear entre su figura y la del "turista" cuando, extasiado ante la "perspectiva abrumadora monumental" de la Exposición, exclama: "Claro está que no para todo el mundo, pues no faltará el turista a quien tan sólo le extraiga tamaña contemplación una frase paralela al famoso Qué d'eau!' (380). El comentario de Darío es una muestra más de lo que Buzard clasifica como corriente de anti-turismo, típica entre los escritores de la época. El ataque al turista se convertirá en algo común entre estos "viajeros tardíos" que reclaman para sí el estatus de viajero independiente que trasiega por el mundo sin caminos señalados ni atracciones marcadas. Como afirma Buzard, 
anti-tourism evolved into a symbolic economy in which travellers and writers displayed marks of originality and 'authenticity' in an attempt to win credit for acculturation[...] Travel's educative, acculturating function took on a newly competitive aspect, as travellers sought to distinguish themselves from the 'mere tourists' they saw or imagined around them. Corresponding, the authentic 'culture' of places - the genius loci- was represented as lurking in secret precincts 'off the beaten track' where it could be discovered only by the sensitive 'traveler', not the vulgar tourist (The Beaten Track 6).

Escritores como Darío, Silva o Gómez Carrillo, al sentir amenazado su estatus de privilegio como viajeros y cronistas, como mediadores culturales entre las "vistas pintorescas" y su público, por la presencia del turista (que aparece como una caricatura o sombra de sí mismos), arremeten contra ellos.

En la crónica dedicada a Roma en Peregrinaciones (1901) podemos encontrar tal representación del turista en este contexto de anti-turismo. Darío describe de esta manera su llegada a Roma:

Mientras me dirijo hacia la Piazza Venecia para tomar el tranvía que ha de conducirme a San Pablo, un ejército cosmopolita para a mi lado, con sus insignias en el pecho y sus guías en la mano. Hablan aquí en alemán, allá en húngaro, más allá en inglés, en español, en francés, en dialectos de Italia, en todo idioma. Son miembros de distintas peregrinaciones que vienen con motivo del Año Santo. Se atropellan, se estrujan, por tomar un puesto en los carros. Veo escenas penosas y ridículas. Ramilletes humanos se desgranan al partir el vehículo[...] Ancianos, hombres de distintas edades, niños, nodrizas con bebés, frailes de todo plumaje, curas de toda catadura, se han desprendido de los cuatro puntos del globo, para venir a visitar santuarios, besar piedras, admirar templos, y sobre todo, ver a un viejecito ebúrneo que alza apenas la diestra casi secular, y esboza bajo la inmensa basílica el ademán de una bendición (217-8).

En el texto de Rubén Darío resulta evidente la representación del turista como un integrante anónimo de la masa, con "sus guías en la mano", como un "ejército" que compone "escenas ridículas", así como el uso de verbos como "atropellar" o "estrujar" para describir sus acciones, que connotan el aspecto destructivo que Darío quiere transmitir a sus lectores. Por otra parte, los turistas son identificados como clientes de una industria que permite el desplazamiento masivo de gente y que, por lo tanto, permite el tratamiento impersonal de tal figura. Karl Baedecker y Thomas Cook representan a los creadores de tal industria y el turista emerge como un producto, como individuo diluido en la pluralidad frente a la individualidad del viajero. Ya he señalado anteriormente cómo uno de los motivos que provocan el rechazo del turista por parte de los modernistas deriva de la tendencia democratizadora del viaje que significa la aparición del turismo. Ante la representación de una noche iluminada con antorchas en el Coliseo romano escribe Darío:

Mas la sonrisa no vacila entre estos matchs de feria al amparo de la democracia igualitaria, y aquellas formidables funciones en que la magnificencia cesárea regaba con sangre la tierra en que se alzaría el árbol simbólico de Cristo. Dicen que hay turistas que se pagan el espectáculo de una iluminación con antorchas y románticos que van en las noches de luna a recordar a Eudoro y Cimodocea. Lo primero es un exceso de Baedecker, lo segundo excesivamente anacrónico (254). 
En José Asunción Silva encontramos una idéntica voluntad de distanciarse de la figura de ese turista que amenaza con su presencia el papel del escritor-viajero hispanoamericano. Tal actitud se refleja en José Fernández, el protagonista de De sobremesa, quien, tras huir de París, busca refugio en Suiza, en las montañas, en "un sitio donde no llegan turistas" (256), como él mismo se ocupa de subrayar. Más adelante, el espectáculo de un grupo de turistas cenando juntos en un hotel le inspira una diatriba en la que no falta la referencia al Baedeker que vimos también en Darío, confirmándonos ese temor generalizado a la pérdida de su autoridad discursiva como viajeros ante los turistas y sus guías:

¡El conjunto cosmopolita de estas mesas redondas de los grandes hoteles y los contrastes disparatados de todas ellas! El menú francés parece un exotismo dada la composición heterogénea de la del Hotel Victoria, donde vivo[...] ¡Oh, personajes que me divertís al observaros y dais a mi imaginación fantaseadora ocasión de forjarme vuestra vida mientras engullo los manjares[...] que recorréis Europa entera, con el Baedeker en una mano y la biblia en la otra, pronunciando el mismo beautiful, beautiful charming, quite charming ante los fiords glaciales de Noruega[...]; viejas que atravesáis los países que os atraen bebiendo el mismo té tibio, devorando los mismos asados sanguinolentos y escribiendo en vuestra clara cursiva las mismas cartas de diez hojas, con las espaldas vueltas a paisajes adorables[...] a quienes alguna agencia de viajes traslada de lugar en lugar para que admiréis sin comprenderlos, los sitios y los edificios designados por la guía Johanne a vuestros entusiasmos de inofensivo turismo[...] todos vosotros engullís la misma sopa de fideos cosmopolita, los mismos asados sospechosos, rociados con el mismo Medoc químico, absorbéis la misma compota de negras ciruelas pasas con que los amables propietarios de los hoteles suizos nutren vuestras hermosas personas en las temporadas de veraneo! (267-8).

El desprecio por la figura del turista resulta claro en el pasaje anterior. Las referencias a las agencias de viajes que organizan tales grupos demuestra el conocimiento del autor acerca del fenómeno del turismo. Y en este caso creo que no sería arriesgado atribuir la diatriba de José Fernández al autor de De sobremesa. El fragmento parece un nuevo intento, por parte de un escritor hispanoamericano que explora Europa, de distanciarse de esa figura en la que se ve reflejado como una parodia. La propia imagen de Silva en París suscita el siguiente comentario en uno de los testigos de sus días en la capital de Francia, Juan Evangelista Manrique: "Como mis estudios no me permitían acompañarlo en sus paseos de turista, convinimos en comer juntos el viernes de cada semana" (32). Tal confusión y promiscuidad entre el papel del turista y del escritor-viajero puede explicar reacciones tan llenas de encono como las de Silva. El escritor hispanoamericano trata de deslindar su aproximación epistemológica a Europa (artística, aristocrática o elitista, y exclusiva) de la aproximación que ha introducido el turismo (democrática, divulgativa y dirigida por una industria de masas). La última decisión, el último gesto de José Fernández antes de que lo encontremos en América, en su interior, rodeado de su colección, consiste en vaciar el interior de su casa en París y empaquetar su colección para cruzar el Atlántico con esa 'portátil Europa', en la feliz y anticipadora expresión de Baltasar Gracián. ${ }^{10}$ A pesar de las

10 "Sirve, pues, la isla de Santa Elena (en la escala de un mundo a otro) de descanso a la portátil Europa, y ha sido siempre venta franca, mantenida de la divina próvida clemencia en medio de inmensos 
feroces críticas al turismo organizado que hemos visto en su narración, con tal gesto Fernández no hace más que repetir uno de los actos que definen la actitud del turista: la apropiación. Como afirma James Buzard

'appropiation' can perhaps best be defined as any action (physical, financial, imaginary) which converts the 'culture' encountered through travel into exchangeable items, tokens of cultural accomplishment that are legal tender in the sign-market of personal acculturation at home. An American's urge to appropriate Europe may find many forms of expression, all of which testify to an anti-touristic sensitivity to or intimacy with European people, places, and things: by buying souvenirs (incluiding works of art of copies of them); by marrying a European spouse; by staking some claim to actual European property; and, if that American is a writer, by structuring travel experience in verbal packages of 'impressions'. In all these ways, one takes part in that whole. Symbols of Europe become commodities that tourists exchange by displaying them to an audience, which responds (or is imagined to respond) by recognizing the tourist as a person of culture. Europe thus appropiated and exchanged becomes 'Europe' (225-226).

Ese "empaquetamiento verbal" de otra cultura a que se refiere Buzard como forma de apropiación tiene su correlato literal en la actitud del protagonista de la novela de Silva, pero la traslación textual tiene lugar en las crónicas que desde Europa envían escritores como Gómez Carrillo o Darío a sus lectores bajo el título común de "Impresiones" o "Sensaciones". Tal visión encaja perfectamente con la definición de la crónica modernista como "mercancía" establecida por Aníbal González. ${ }^{11}$

En uno de sus libros de viajes La sonrisa de la esfinge (1917), Gómez Carrillo advierte de entrada al lector que su mirada, su visión del mundo, no corresponde a la del turista. Un epígrafe en el espacio liminar del texto le permite resaltar tal puntualización y dice mucho de la importancia que le concede su autor. Se trata de un fragmento de la obra Corrêspondencia de Fradique Mendes, del escritor portugués Eça de Queiros:

Lo que hacía en estos viajes tan fecundos como enseñanza era su rápida y cariñosa simpatía hacia todos los pueblos. Nunca visitó países a la manera del detestable touriste, para notar desde lo alto y maliciosamente "los defectos", esto es, las divergencias de este tipo de civilización media y genérica de donde salía y que merecían su preferencia. Fradique amaga al punto las costumbres, las ideas, los prejuicios de los hombres que le rodeaban, y fundiéndose con ellos en su modo común de pensar y de sentir, recibía una lección directa y viva de cada sociedad en que vivía (En La sonrisa de la esfinge 9).

golfos, a las católicas flotas del Oriente" (El Criticón 65). Con respecto a la actitud del escritor modernista asimilado a la figura del coleccionista en su viaje a Europa, véase Cristóbal Pera, "José Asunción Silva: un coleccionista hispanoamericano en París".

11 "Como género periodístico, la crónica está sujeta a exigencias de actualidad, de novedad y a lo que podríamos llamar 'leyes de la oferta y la demanda', ya que , desde el punto de vista del periodismo, la crónica es una mercancía[... ] para ser más específicos, la crónica es una mercancía de lujo: su valor es menos informativo que recreativo" (González 75). 
Gómez Carrillo será el gran guía del turismo literario y cultural de masas en Hispanoamérica. En su texto Sensaciones de París yde Madrid(1900), comienza arrogándose la facultad de oráculo, de ser partícipe del secreto sobre la ciudad que pocos conocen. De nuevo se repite la intención de estos escritores de deslindar su aproximación epistemológica de la del turista. Ya en el texto de Sarmiento sobre París se podía leer una advertencia parecida: "Yo que estoy a la altura de París, cosa que experimentan otros antes de llegar, no presto atención a las habladurías; estoy iniciado en el secreto; sé lo que pocos saben". ("París" 130). Pero si en Sarmiento la ciudad está problematizada y el escritor no se siente capaz de aprehender la complejidad y variedad de las ideas en circulación ni la velocidad de la vida ciudadana, en Gómez Carrillo nos encontramos con un París que responde a una imagen fijada tanto a nivel ideológico como urbano. Si Sarmiento se puede asimilar a la imagen del explorador, Gómez Carrillo se acerca más a la imagen del guía turístico.

En el plano urbanístico el mapa de París que compone Gómez Carrillo a través de sus crónicas, fijado por el centro de la torre Eiffel, simplifica la ciudad en tres áreas que representan ciertos valores: Montmartre (placer, vicio), el Barrio Latino(bohemia, escritores simbolistas) y el bulevar (centro del teatro y el periodismo, lugar de confluencia del cosmopolitismo). En mi opinión, esta simplificación de París, tanto a nivel urbanístico como cultural es también fruto de la influencia de las guías de viajes (entre ellas, la más famosa la de Baedecker) que, como veremos enseguida, Gómez Carrillo conocía muy bien.

Resulta evidente, a la vista de estos textos, que escritores como Darío, Silva o Gómez Carrillo sienten amenazado su estatus de cronistas ante la masiva aparición de la figura del turista. Tal temor está provocado por la extrema proximidad entre los papeles que representan, lo que provoca una reacción de rechazo que, sin embargo, termina por aproximarlos aún más al verdadero papel del turista. Como señala Jonathan Culler en su artículo titulado "The semiotics of Tourism", la figura del turista representa uno de los ejemplos más claros del semiótico en nuestra cultura.

The tourist is interested in everything as a sign of itself, an instance of a typical cultural practice: a Frenchman is an example of a Frenchman, a restaurant in the Quartier Latin is an example of a Latin Quarter restaurant, signifying 'Latin Quarter Restaurantness'. All over the world the unsung armies of semiotics, the tourists, are fanning out in search of signs of Frenchness, typical Italian behavior, exemplary Oriental scenes[...] In their most specifically touristic behavior, however, tourist are the agents of semiotics: all over the world they are engaged in reading cities, landscapes and cultures as sign systems (155).

El examen de la obra de Gómez Carrillo y su papel en la divulgación de la ciudad de París a la luz de estas reflexiones sobre el turista, nos permite apreciar su función como la de un semiótico. Si, como señala Jonathan Culler, se reconoce que el deseo de no ser tan turistas como otros turistas forma parte del hecho de ser turista (158), entonces podemos explicarnos las reacciones de Darío, Silva y Gómez Carrillo.

Otro aspecto del turismo en la cultura capitalista moderna es el de la distinción entre lo "auténtico" y lo "no auténtico". Como afirma Culler, "the authentic is a usage perceived as a sign of that usage, and tourism is in large measure a quest for such signs" (159). Gómez Carrillo, tan sagaz siempre en el reconocimiento de los nuevos elementos de la vida 
moderna, es muy consciente de tal búsqueda de "autenticidad" y, si no lo reconoce en su obra, lo aprecia en la obra de otros. En Sensaciones de París y de Madrid (1900), al comentar un libro de viajes de Jules Lorrain sobre España, escribe:

Barcelona no podía gustar al viajero que iba en busca de las imágenes ideales de Musset y de los paisajes fabulosos de Gautier[...] Por mi parte yo no veo en él sino un simple esbozo impresionista y personal, que pone en evidencia la desilusión experimentada por un viajero romántico que va en busca de rincones raros, de paisajes extraños, y que se encuentra en una sucursal de la Avenida de la Opera. ¿De qué se queja, en efecto, ese viajero? De ver muchos teatros, muchas peluquerías, y mucha gente que va a los teatros y a los cafés[...] 'Comercio de cosas superfluas y lujosas' — dice. El viajero que pasa dos días en París puede decir lo mismo. El boulevard es una inmensa calle de confiteros, y de peluqueros, y de teatros y de cafés[...] Los trabajadores de Barcelona no están en la Rambla, ni los de París en el Boulevard (43).

El mismo reproche que le hace a Lorrain por el hecho de querer encontrar en Barcelona la España de pandereta difundida por Merimeé podría aplicarse al propio Gómez Carrillo, quien abre el libro de viajes al oriente, La sonrisa de la esfinge (1913), con la desilusión del viajero que se siente engañado al no encontrar la "experiencia de lo auténtico" en un país extranjero.

La primera impresión, en las grandes ciudades orientales, es casi siempre desilusionante. Llega uno con el alma llena de ensueños maravillosos, con la memoria poblada de recuerdos encantados[...] Llega uno buscando al visir de las mil y una noches que va a abrirle las puertas de un alcázar[...] Y, como en todas partes los hoteles para viajeros occidentales están en lo que se llama el barrio europeo, la decepción es cruel[...] Y más allá aparece, enorme y ruidosa, como continuación del parque, la plaza de la Opera, y del Tribunal Mixto, y del Crédito Lionés y de la Caja de la Deuda. ¡Qué cosas para una ciudad de mamelucos y de califas! Los letreros áureos de las tiendas, brillan anunciando agencias americanas, cervecerías germánicas, barberías parisienses. Todas son claras letras latinas. Nada nos dice que nos hallamos lejos de Europa. Nadie parece poner empeño en darnos la ilusión de lo raro, de lo vistoso, de lo remoto, de lo exótico. Las aceras están llenas de gente vestida a la moda de Londres o a la moda de Paris[... que va de prisa, Dios sabe a qué citas de negocio (12-15).

El pasaje anterior revela claramente la asimilación de figura de Gómez Carrillo a la del turista en busca de una experiencia "auténtica". El deseo de tener tal experiencia, aún a costa de ser engañado ("Nadie parece poner empeño en darnos la ilusión de lo raro, de lo vistoso, de lo remoto, de lo exótico"), resulta muy significativo.

En mi opinión, uno de los elementos que contribuyeron al gran éxito de Gómez Carrillo como cronista ante un público tan amplio como el hispanoamericano estriba en su sagaz intuición para percibir fenómenos nuevos en el funcionamiento de la sociedad capitalista moderna. Uno de tales fenómenos es el turismo y la prueba de su temprano interés por el tema es la crónica titulada "La psicología del viaje", que comienza de la siguiente manera: "La afición por los viajes va convirtiéndose, según las estadísticas de las agencias ferroviarias y marítimas en una pasión inquietante" (7). Mas adelante encontramos un 
pasaje en donde la fascinación del cronista, de ese flâneur universal, por el turismo se convierte en una loa de las guías de turismo como sucedáneos (o tal vez como competencia) de la literatura. El siguiente pasaje confirma ese desplazamiento discursivo que señalaba Behdad desde las narraciones de viaje a las guías turísticas.

En realidad el más bello libro de viajes modernos que existe no es obra de un gran escritor. Su título es vago, incoloro y cambia según es una Compañía de seguros marítimos o una Sociedad de hoteleros quien lo publica. Suele llamarse Kosmos, o The World, o La vuelta al mundo[...] Eso no importa. Como no tiene una linea de texto literario, como no ofrece mas que nombres de ciudades o de paisajes al pie de las láminas, nada en su literatura nos choca. Desde la primera página es un hechizo, una droga, una alucinación[...] Era en un Banco. Yo había ido a cobrar un cheque. En una mesa había un enorme infolio con un título inglés que significaba algo así como el universo en la mano[...] Nada de texto. Nada más que vistas. Vistas por todas partes, vistas exóticas, vistas fantásticas[...] iQué se yo[...]! Todo el universo estaba ahí, entre mis manos. Y yo le recorría embelesado ("La psicología del viaje", citado por González 173). ${ }^{12}$

Acerca del turismo como fenómeno específico de la modernidad en la cultura occidental contamos con el estudio semiótico de Dean MacCannell, The Tourist: A New Theory of the Leisure Class. En su teoría encontramos ideas que nos confirman que ciudades como París son abordadas por gran parte de los escritores hispanoamericanos como un catálogo en donde recuperar su condición de herederos de una cultura:

The touristic integration of society resembles a catalogue of displaced forms[...] The diferentiations are the attractions[...] and bring the people liberated from traditional attachments into the modern world where, as tourist, they may attempt to discover or reconstruct a cultural heritage or a social identity (13). ${ }^{13}$

\footnotetext{
${ }^{12}$ Aníbal González señala el hecho de que este texto parece prefigurar "El Aleph" de Borges. Otro hecho significativo estriba en la fijación de Gómez Carrillo por las imágenes del catálogo de turismo. La repetición de la frase "Nada de texto" nos sugiere hasta qué punto era consciente el cronista de la superfluidad (o suplementariedad, si seguimos a Derrida) de la crónica de viajes. Aníbal González apunta sagazmente el hecho de que "cuando la literatura emerge del interior, dispuesta a recuperar sus dominios discursivos, éstos ya han sido ocupados por formas nuevas de representación, como lo son la fotografía y el cine, que satisfacen mejor las exigencias de la epistemología empirista que está a la base de casi todo el quehacer literario del siglo XIX. La toma de conciencia de este hecho es, en parte, uno de los elementos que dan impulso a las vanguardias: para poder sobrevivir, la literatura y las artes plásticas tienen que inventar, adoptar o adaptar nuevas formas, nuevas teorías de representación" (174).

${ }^{13}$ Con respecto al concepto de "catálogo" como aproximación del viajero o turista a una realidad diferente, Daniel Canogar, en op. cit., dice lo siguiente sobre las Exposiciones Universales: "La Gran Exposición Internacional (Londres, 1851) catalogaba, como un museo de ciencias naturales, la diversidad del globo bajo un mismo techo. Este impulso enciclopedista significaba inevitablemente una simplificación estereotipada de la heterogeneidad y riqueza propia de cada nación. El imperialismo expansionista de las potencias europeas se legitimaba por el montaje contiguo de países geográficamente distantes y filosóficamente opuestos. El exótico "primitivismo" de las naciones coloniales participantes quedaba malparado cuando era comparado con los últimos avances tecnológicos europeos" (29).
} 
MacCannell trata de establecer el paralelo entre la definición del signo de Pierce y la relación entre el turista, el marcador y la vista de la siguiente manera:

[representa / algo / para alguien] signo

[marcador / vista / turista] atracción.

Gómez Carrillo descubrió pronto el valor de lo que MacCannell llama "marcador" (marker) de una "vista" (sight). Jonathan Culler resume así este elemento definido por MacCannell:

These reproductions are what MacCannell in his account of the semiotic structure of the touristic attractions calls markers. Like the sign, the touristic attraction has a triadic structure: a marker represents a sight to the tourist. A marker is any kind of information or representation that constitutes a sight as a sight: by giving information about it, representing it, making it recognizable. Some are "on sight" markers[...] some are mobile markers, such as pamphlets and brochures designed to draw people to the site, give information at the site, and serve as souvenirs or representations of the site (159).

Tales marcadores (como los folletos de vistas sin texto de que habla Gómez Carrillo) mediante un proceso de sacralización de la vista ("sight sacralization") son los que ponen en marcha al turista en busca de la vista auténtica de un original. Sin embargo, el marcador sigue siendo de capital importancia una vez que el turista confronta la vista real, ya que seguramente la comparará con el marcador que lo llevó allí. La fascinación que Gómez Carrillo parece mostrar por las guías y los folletos de turismo explica en cierto modo el hecho de que lo hayamos asimilado a la figura de un guia turístico del París sacralizado y mitificado que existía a lo largo y ancho de Hispanoamérica. Consciente de su posición, el cronista se dedicó a crear "marcadores" (crónicas) de las "vistas" que su público demandaba. ${ }^{14}$ Es una prueba más del desplazamiento discursivo que se produce en la literatura de viajes desde las narraciones de viajes a las guías turísticas provocado por el "deseo" del público. Y gran parte de esas "vistas" no son monumentos, ni cabarets, sino figuras de escritores franceses cuyos seguidores eran legión. Gómez Carrillo ofrece a sus lectores, a través de sus crónicas, la posibilidad de echar una ojeada tras los bastidores del espectáculo codificado de una ciudad como París. El les promete una "experiencia auténtica". Como señala Jonathan Culler a este respecto,

in their quest for an authentic experience, tourists want to see the inside of things, so social and economic arrangements are made to take them behind the scenes, ranging from guided tours of the Paris sewers, the morgue, or the stock exchange to schemes whereby small

\footnotetext{
${ }^{14}$ Como señala María Luisa Bastos, en "La crónica modernista de Enrique Gómez Carrillo o la función de la trivialidad": "Escritor exitoso adherido a las tendencias en boga, empezó Gómez Carrillo siendo propagandista eficaz de esas tendencias como ya lo demostró John W. Kronik. Decía Gómez Carrillo de sus admirados carteles de Chéret y de Mucha que educaban las retinas de la masa, y en algo equivalente nos hacen pensar sus textos. Como affiches, esos escritos enseñaban dónde estaban las buscas estéticas de la época" (76).
} 
groups of tourist willing to pay handsomely for the privilege can stay at a ducal castle and breakfast with the duke (165).

Además de su asimilación a la ciudad y de su presunción de que conoce "el secreto" de París, Gómez Carrillo ofrece a sus lectores un "tour" por el París "auténtico" de los escritores, de la vida nocturna y de la última moda femenina. A lo largo y ancho de Hispanoamérica, los lectores de sus crónicas podían sentir la emoción de participar en una "experiencia auténtica", de disfrutar de los métodos y los medios del creciente turismo sin llegar a sentirse turistas.

Con idéntica actitud a la del turista que se lanza a reconocer (no a explorar) un país extraño a través de las guías turísticas en donde lo pretendidamente auténtico y pintoresco se le presenta marcado, escritores modernistas como Gómez Carrillo o Darío, se lanzan a "reconocer" los "hitos" señalados en el territorio textual de la modernidad a través de sus crónicas y de las colecciones de éstas. Su modelo discursivo ya se ha desplazado del viajero al turista.

Para confirmar la permeable presencia de las guías turísticas como modelos textuales entre los escritores de la época basta con echar un vistazo a algunos pasajes en donde escritores como Darío, Vicuña Subercaseaux o el propio Gómez Carrillo relacionan la visión de la ciudad de París con la lectura de una guía turística. Como señalaba Jonathan Culler, el papel de estos escritores-turistas es el de "agents of semiotics: all over the world they are engaged in reading cities, landscapes and cultures as sign systems". Es la visión de ciudades como París que pueden ser leídas textualmente como se lee una guía turística, en este caso la famosa guía Baedecker. En una crónica para La Nación de Buenos Aires, publicada en 1887 y titulada "Zola trabaja", escribe Rubén Darío:

Pedro Froment está por reaparecer. Yo no sé lo que haráahora Pedro Froment. Probablemente ha dejado su Baedeker, pues no lo necesita para París. De todos los Parises que aparecen en el innumerable desfile de los Rougon-Macquart, se compone el suyo, que será más vasto, más detallado, más minucioso. Vereis cosas exactas como en una guía, y cosas líricas como en un poema. La gran ciudad de Hugo a través del temperamento de Zola, el ideal de la obra de arte medanista, la torre de Babel del naturalismo: eso será, eso me parece que será Paris (Mapes, Escritos inéditos de Rubén Dario 127).

En estas palabras de Darío, "Vereis cosas exactas como en una guía, y cosas líricas como en un poema", se encuentra resumido el propósito a que aspira Gómez Carrillo en sus crónicas. A comienzos del siglo XX otro escritor hispanoamericano, B. Vicuña Subercaseaux, retoma la imagen en su libro sobre París, La ciudad de las ciudades:

He querido comprobar cómo puede leerse la historia de París recorriendo sus calles. Cada monarca, cada hombre, cada época, han dejado su huella. El sentimiento de la tradición ha conservado esa huella. Partiendo de la isla (la Cité), por un lado hacia el Arco del triunfo, y por otro hacia la Plaza de la Nación, con la ayuda de un Baedecker, se encuentran vestigios que nos enseñan, rápida y agradablemente, una historia de mil años (47). 
Por último, el propio Gómez Carrillo, en el libro de crónicas mencionado anteriormente, La sonrisa de la esfinge, hace referencia a su lectura de la ciudad de Constantinopla en una guía Baedecker y aduce que su decepción ya le había sido anunciada.

Así, yo me hallo ahora en mi ventana del Hotel Continental, triste, cual un engañado. Eso que aparece ante mis ojos, no obstante, es lo que el señor Baedecker tuvo la gentileza de anunciarme (14).

En estos pasajes aparece patente la influencia que el fenómeno del turismo ejerce en estos escritores y de qué manera condiciona su lectura textual de ciudades como París, Roma o Constantinopla. Si existía una imagen de París que se transmitía a través de textos, uno de esos textos es la lectura de la ciudad llevada a cabo por las guías turísticas que tanto apasionaron a Gómez Carrillo. Así pues, la transmisión de ciudades como París a través de las crónicas, estará ciertamente mediatizada por tales guías y folletos turísticos. Acerca de esa guía ideal del turista comentaba Gómez Carrillo en "La psicología del viaje" que, "como no tiene una línea de texto literario, como no ofrece más que nombres de ciudades o de paisajes al pie de las láminas, nada en su literatura nos choca". La referencia a la "ausencia de texto" me parece significativa en este pasaje. Tal vez es ahí en donde el cronista vio el único terreno discursivo que le dejaban.

Desde principios de este siglo ya puede apreciarse en muchos escritores hispanoamericanos el eco de esa transformación discursiva que se ha producido desde la visión elitista del "viajero decimonónico" hacia una más moderna "mirada del turista", fruto de la democratización e institucionalización del viaje que trae consigo el turismo organizado. Lo primero que llama la atención es cómo en su mayoría, los escritores hispanoamericanos que viajan a Europa desde principios de siglo confrontan el fenómeno del turismo con la naturalidad de quien asume ese papel que tanto rechazo provocaba en Darío o en Silva. Son herederos, en ese sentido, de Gómez Carrillo. Uno de los textos más reveladores es un artículo publicado por Alejo Carpentier en la revista Carteles de la Habana en 1939 y titulado "La Habana vista por un turista cubano". En dicho artículo Carpentier juega a asumir el papel de turista a su vuelta a la Habana, tras once años de ausencia, y a aplicar la visión, aprendida tras sus viajes por Europa, a su ciudad natal:

Ahora, turista en mi propia tierra, aprendo a considerar la Habana con un respeto ajeno a todo sentimiento íntimo y personal de cariño. Me maravillo ante su multiplicidad, ante la diversidad de la gente que la puebla, ante su pintoresquismo de buena ley (19).

El escritor cubano comienza apreciando el "pintoresquismo" de su propia tierra y decide aplicar a su viaje a La Habana

los métodos de indagación que nos habíamos impuesto al descubrir - todo viaje es un descubrimiento para uso propio- ciudades como Madrid, Toledo, Amberes o Tours[...] El juego resulta extremadamente divertido, y en ciertos casos suele mostrarse revelador. Porque confieso que La Habana me ha revelado cosas que yo no había visto o "no había sabido ver" hace once años ¿por falta de curiosidad? Tal vez[...], ya que una de las facultades que Europa[...] desarrolla en su más alto grado es la curiosidad (19-20). 
De nuevo, la vuelta de Europa ha cambiado la mirada del escritor, no sólo con respecto a la historia y la identidad de su país (como ocurre de manera especialísima en escritores como Carpentier o Asturias), sino en algo tan simple como la mirada del viajero que asume ahora su papel de turista sin sentir amenazada su autoridad discursiva. ${ }^{15}$ Y como Gómez Carrillo, Carpentier decide en París comenzar su viaje turístico a La Habana por "su lógico punto de partida: la agencia de viajes" (20). Todos los componentes del fenómeno turístico que hemos ido viendo en los textos de Darío o de Gómez Carrillo encuentran aquí su correlato. En la sección titulada "Thos. Cook and sons", Carpentier nos recuerda la visita asombrada del escritor guatemalteco a la agencia de viajes y su fascinación por los catálogos:

En esta esquina del bulevar de la Madeleine y de la Rue Scribe, reina todopoderosa y peligrosamente insinuante L'invitation au voyage. Poema de Baudelaire. Música de Duparc[...] Carteles dibujados con diabólica habilidad nos invitan a visitar países[...] Los minaretes argelinos, las palmeras de Madera, los danzarines de Rumania, los pullman del Ave Azul, las piscinas del trasatlántico, el Pan de Azúcar, el Hotel Frontenac, las playas de California, y sobre todo el triángulo isósceles y la esfera de la Exposición de New York, aparecen en las vitrinas de las oficinas de la Agencia Cook, como otras tantas invitaciones a abandonar la atmósfera de pesadilla guerrera en que vivimos[...] (20).

La mención de Baudelaire junto a las vistas proclamadas por los folletos turísticos nos recuerda las palabras de Darío cuando escribía "Veréis cosas exactas como en una guía, y cosas líricas como en un poema", y el embelesamiento de Gómez Carrillo cuando, ante los folletos de propaganda turística, se sentía con el "universo en la mano[...] Nada de texto. Nada más que vistas. Vistas por todas partes, vistas exóticas, vistas fantásticas[...]”. El escritor ya no lucha por preservar su estatus elitista de viajero, se ha dejado seducir por la industria turística y adopta voluntariamente su punto de vista. El texto de Carpentier merece, para otra ocasión, un análisis más detallado, ${ }^{16}$ que nos mostraría cómo su familiaridad con

\footnotetext{
${ }^{15}$ Este viaje de Carpentier a La Habana desde París es comparable al viaje que, tras una larga ausencia de años, realizó Rubén Darío a Nicaragua en 1907, plasmado en su libro El viaje a Nicaragua e Intermezzo tropical. Publicado originalmente en Biblioteca Ateneo (Madrid, 1909). Aunque Darío no menciona en ningún momento la figura del turista, es evidente que la mirada con que vuelve a ver su país está marcada por la búsqueda del "pintoresquismo". Tal evidencia hace que en la introducción a una moderna edición del mismo texto, publicada en Nicaragua, Fidel Coloma González afirme que Dario "mira con ojos de turista a las campesinas y el laboreo de café" (55). Y sin duda en esta ocasión pensaba en el público europeo. Más interesante aún puede resultar el hecho de que Darío planeara la estructura del libro como una guía turística. Fidel Coloma González aporta la información suficiente para sustentar tal hipótesis: "Darío envía a La Nación el primero de los diez capítulos que integraban inicialmente este libro, el 22 de julio de 1908; la serie continúa hasta 'principios de 1909'. El 12 de enero siguiente escribe a Santiago Argüello que el libro 'se está publicando', que piensa hacer una edición en inglés, para la cual quiere ilustraciones: 'fotografía de paisajes, de monumentos y de personalidades del país', de 'damas bellas'. Concebía pues el libro como una especie de guía o de descripción histórica, geográfica, cultural y social de Nicaragua” (53).

${ }^{16}$ Este trabajo forma parte de un amplio proyecto de estudio sobre el tema del turismo y la literatura en Hispanoamérica en el que trabajo actualmente.
} 
el fenómeno del turismo le permite reflexionar sobre el "pintoresquismo" de su propia tierra. Pero me gustaría señalar la paradoja de un Carpentier que asume hasta tal punto su papel de turista que llega a imitar una de sus más genuinas características: la apropiación. En este caso se trata de su propia ciudad natal: "habéis coleccionado imágenes de viejos balcones o partidos umbrosos en La Habana antigua; habéis visitado edificios históricos o santuarios, culminando el necesario e insustituible itinerario del turista[...]" (38).

Sería larga la lista de escritores hispanoamericanos que se han dejado seducir por este fenómeno tan característico de la modernidad ( $\mathrm{y}$, por supuesto, de la posmodernidad, ${ }^{17}$ aunque no entraremos ahora en ello). Podríamos traer a colación libros de viaje como el de Arturo Uslar Pietri, El globo de colores, en el que la sección dedicada al Oriente se titula "Un turista en el Lejano Oriente", algo que los modernistas jamás habrían osado hacer. O mencionar la constante obsesión de Cortázar por este fenómeno sociológico cuando afirma: "El turismo juega con sus adeptos, los inserta en una temporalidad engañosa, hace que en Francia salgan de un bolsillo las monedas sobrantes, que en Holanda se busque vanamente un sabor que sólo da Poitiers" ("La barca" 162). Cortázar demostró en cuentos como "La isla al mediodía" o "La barca o nueva visita a Venecia", cómo el turismo puede no solo proporcionar materiales para la ficción, sino promover reflexiones sobre las cambiantes relaciones humanas en la sociedad contemporánea.

Igual podría decirse de García Márquez, quien dedicó uno de sus últimos libros, Doce cuentos peregrinos, a viajeros hispanoamericanos por Europa que ejercen en muchos casos de turistas. Pero la preocupación de García Márquez por el turismo ha sido una constante en sus textos y puede rastrearse fácilmente desde sus primeros artículos periodísticos. En una crónica para El Espectador fechada en Roma, en diciembre de 1955 y titulada "Comienzan a recogerse pruebas para beatificar a Pio XII", escribe un párrafo que nos remite a la crónica de Darío sobre el mismo tema y publicada medio siglo antes. Escribe García Márquez:

En el patio de piedra con capacidad para 2.000 personas enlatadas, los funcionarios del castillo acomodan a los visitantes como sardinas. Allí llegan, atropellándose, los más diversos y extraños géneros de frutas que dan las Viñas del Señor. Llegan los alemanes con sus morrales y sus pantalones de cuero. Llegan los norteamericanos con su complejo baratillo de instrumentos fotográficos y su libro para conocer a Roma en siete días[...]

\footnotetext{
${ }^{17}$ Como señala Caren Kaplan, "Tourism heralds postmodernity; it is a product of the rise of consumer culture, leisure, and technological innovation. Culturally, exile is implicated in modernist high art formations while tourism signifies the very obverse position as the mark of everything commercial and superficial" (27). Kaplan plantea una cuestión que me parece muy relevante en el ámbito de la literatura hispanoamericana del siglo XX, y es la mistificación de cierto tipo de desplazamiento que reclaman unilateralmente ciertos escritores (exilio), frente a la desvalorización de otros tipos de "desplazamiento" como el turismo: "What is at stake in contemporary Euro-American assertions of oppositional qualities between these categories? Looking at exile and tourism as cultural representations aids an analysis of the social practices of different kinds of displacement and travel, moving beyond mystification to more historically and culturally nuanced interpretations" (27). Un escritor en donde se puede apreciar este conflicto, precisamente por su borroso y autoconferido estatus de "exiliado", es Julio Cortázar.
} 
Todos entran atropelladamente como los corderos de Dios a un estrecho corral de piedra cerrado por los cuatro costados (270).

La confrontación con el fenómeno turístico en el recinto sagrado, en la sede de la civilización occidental, provoca visiones coincidentes en ambos escritores. Invito al lector a cotejar más detalladamente el texto de García Márquez con la crónica de Darío, citada más arriba. Tan solo un par de frases del texto de Darío nos revelan cómo el término "atropellar" es compartido por ambos escritores para connotar los aspectos negativos del turismo. Escribía Darío: "Son miembros de distintas peregrinaciones que vienen con motivo del Año Santo. Se atropellan, se estrujan, por tomar un puesto en los carros. Veo escenas penosas y ridículas. Ramilletes humanos se desgranan al partir el vehículo[...]" (217).

En septiembre de 1956, García Márquez escribe un artículo para la revista venezolana Élite, titulado "Verano en París: turistas y pin-ups", en el que demuestra su conocimiento acerca de los aspectos comerciales y sociológicos del turismo. Años más tarde, en sus artículos para El País, vuelve a dedicarle espacio al mismo tema entre sus reflexiones y demuestra la ambigüedad con la que el escritor sigue encarando dicho fenómeno de masas, dependiendo de su posición de espectador o de usuario. En un artículo titulado "La dura vida del turista" (1982), narra un viaje a Grecia acompañado de su esposa y cómo las obligaciones que impone el tour organizado impiden cualquier intento por su parte de explorar libremente el país visitado en busca de la autenticidad. Es el eco persistente de esos "viajeros tardíos" en busca de románticos encuentros y experiencias exóticas que saben que no hallarán. García Márquez tiene

la impresión de ser prisionero de un organismo de relojería. Estas virtudes son ideales para el turista cuadrado, al cual hay que indicarle todo. Pero quienes tenemos la pretensión de hacer las cosas de un modo distinto, tropezamos sin remedio con las talanqueras del orden (278).

El propio García Márquez en un artículo publicado en el mismo periódico un año más tarde, y titulado "Viendo llover en Galicia" (1983) sintetiza esa ambigüedad ante el fenómeno del turismo que hemos visto reflejada en muchos escritores:

No sé de dónde viene la vergüenza de ser turista. A muchos amigos, en pleno frenesí turístico, les he oído decir que no quieren mezclarse con los turistas, sin darse cuenta de que, aunque no se mezclen, ellos son tan turistas como los otros. Yo, cuando voy a conocer algún lugar sin disponer de mucho tiempo para ir más a fondo, asumo sin pudor mi condición de turista. Me gusta inscribirme en esas excursiones rápidas, en las que los guías explican todo lo que se ve por las ventanas del autobús, a la derechay a la izquierda, señores y señoras, entre otras cosas porque así sé de una vez todo lo que hay que ver después, cuando salgo solo a conocer el lugar por mis propios medios (409).

Este texto de García Márquez nos confirma cómo en la actualidad el escritor viajero no tiene más remedio que asumir que ha sido absorbido como turista por esas masas humanas que "se atropellan" y "se estrujan" peregrinando en busca de una "vista". 


\section{BiBLIOGRAFÍA}

Anglo-American Guide to Exhibition Paris, 1900. Londres: Heinemann, 1900.

Bastos, María Luisa. "La crónica modernista de Enrique Gómez Carrillo o la función de la trivialidad." Sur 350-351 (enero-diciembre, 1982): 65-88.

Behdad, Ali. Belated Travelers: Orientalism in the Age of Colonial Dissolution. Postcontemporary Interventions. Durham y Londres: Duke University Press, 1994.

Buzard, James. The Beaten Track: European Tourism, Literature, and the Ways to Culture, 1800-1918. Oxford: Oxford University Press, 1993.

Buzard, James. "A Continent of Pictures: Reflections on the 'Europe' of NineteenthCentury Tourists." PMLA 108/1 (January, 1993): 30-44.

Canogar, Daniel. Ciudades efimeras: Exposiciones universales; espectáculo y tecnología. Madrid: Julio Ollero Editor, 1992.

Carpentier, Alejo. "La Habana vista por un turista cubano". El amor a la ciudad. Madrid: Alfaguara, 1996. 17-58.

Coloma, Fidel. "Introducción”. Rubén Darío, El viaje a Nicaragua e Intermezzo tropical. Managua: Nueva Nicaragua, 1987.

Cortázar, Julio. "La barca o nueva visita a Venecia". Cuentos Completos 2. Madrid: Alfaguara, 1994. 161-188.

Culler, Jonathan. "The Semiotics of Tourism". Framing the Sign: Criticism and Its Institutions. Oklahoma Project for Discourse and Theory. Oxford, Inglaterra y Norman: University of Oklahoma Press, 1988.

Darío, Rubén. Peregrinaciones. París: Librería de la Vda. de Ch. Bouret, 1910. El viaje a Nicaragua e Intermezzo tropical. 1909. Managua: Nueva Nicaragua, 1987.

Fombona Iribarren, Jacinto Rafael. El texto de viajes modernista: Viajeros hispanoamericanos y la construcción de Europa. Dissertation. Yale University, 1994. Ann Arbor: Dissertation Abstracts International, 1994.

García Márquez, Gabriel. Doce cuentos peregrinos. México, D.F.: Editorial Diana, 1992. "La dura vida del turista". Notas de prensa: 1980-1984. Barcelona: Mondadori, 1991. 277-279.

"Viendo llover en Galicia". Notas de prensa: 1980-1984. Barcelona: Mondadori, 1991. 408-410.

"Comienzan a recogerse pruebas para beatificar a Pio XII". Obra periodística Vol.

4: De Europa y América (1955-1960). Barcelona: Brugera, 1983. 267-272.

"Verano en París: Turistas y 'Pin-ups"”. Obra periodística Vol. 4: De Europa y América (1955-1960). Barcelona: Brugera, 1983. 404-407.

Gómez Carrillo, Enrique. La sonrisa de la esfinge. Madrid: Casa Editorial Calleja, 1917. Sensaciones de Paris y de Madrid. Paris: Garnier Hermanos, Libreros-Editores, 1900.

"La psicología del viaje". El primer libro de las crónicas. Obras completas. Madrid: Mundo Latino, 1919. 7-35.

González, Aníbal. La crónica modernista hispanoamericana. Madrid: José Porrúa Turanzas S.A, 1983. 
Gracián, Baltasar. El Criticón. Madrid: Cátedra, 1980.

Grünfeld, Mihai. “De viaje con los modernistas". Revista iberoamericana LXII/175(1996): 351-366.

Hajjaj, Karima. "Crónica y viaje en el Modernismo: Enrique Gómez Carrillo y El encanto de Buenos Aires". Anales de Literatura Hispanoamericana 23 (1983): 27-42.

Hozven, Roberto. "Domingo Faustino Sarmiento". Historia de la literatura hispanoamericana II: del romanticismo al modernismo. Luis Iñigo Madrigal, ed. Madrid: Cátedra, 1987. 427-445.

Kaplan, Caren. Questions of Travel: Postmodern Discourses of Displacement. PostContemporary Interventions. Durham y Londres: Duke University Press, 1996.

MacCnnell, Dean. The Tourist: A New Theory of the Leisure Class. Nueva York: Shocken Books, 1976.

Manrique, Juan E. "José Asunción Silva (recuerdos íntimos)". Revista de América 20 (París, enero de 1914).

Mapes, E. K., ed. Escritos inéditos de Rubén Dario. Nueva York: Instituto de las Españas en los Estados Unidos, 1938.

Murcia, Claude. "Le París fin de siêcle de Gómez Carrillo". Paris et le phenomene des capitales littéraires. Carrefour ou dialogue des cultures 2. Pierre Brunel, ed. II vols. París: Université de Paris-Sorbonne-Paris IV, 1984. 819-829.

Oviedo, José M. Historia de la literatura hispanoamericana: I. De los orígenes a la Emancipación. Madrid: Alianza Editorial, 1995.

Pera, Cristóbal. Modernistas en Paris: el mito de Paris en la prosa modernista hispanoamericana. Berna: Peter Lang, 1997.

"José Asunción Silva: un coleccionista hispanoamericano en París". Cuadernos Hispanoamericanos 556 (octubre, 1996): 115-124

Pietri, Uslar. El globo de colores. Caracas: Monte Ávila Editores, 1975.

Pratt, Mary Louise. Imperial Eyes: Travel Writing and Transculturation. Londres y Nueva York: Routledge, 1992.

Romero, José Luis. Latinoamerica: las ciudades y las ideas. Buenos Aires: Siglo XXI, 1976.

Ross, Kathleen. "A Natural History of the Old World: the Memorias of Fray Servando Teresa de Mier”. Revista de Estudios Hispánicos (Vassar, octubre de 1989): 87-99.

Sáinz de Medrano, Luis. "Los viajes de Rubén Darío por Hispanoamérica". Anales de Literatura Hispanoamericana 23 (1994): 83-106.

Sarmiento, Domingo Faustino. "París". Obras: Viajes por Europa, Africay America. París: Belin Hermanos, Editores, 1909. V: 114-147.

Sarmiento, Domingo F. Viajes: De Valparaíso a París. Vol. I de 2 vols. Buenos Aires: La cultura argentina, 1922.

Schade, George D. "Los viajeros argentinos del ochenta". Indice X/28 (1984): 82-103.

Silva, José Asunción. De sobremesa. Obra completa. Héctor H. Orjuela, ed. Colección Archivos. Madrid: Consejo Superior de Investigaciones Científicas, 1990. 227-351.

Todorov, Tzvetan. The Conquest of América. Nueva York: Harper Collins, 1984.

Vicuña Subercaseaux, B. La ciudad de las ciudades: correspondencias de París. Santiago de Chile: Sociedad "Imprenta y litografía Universo", 1905. 
Viñas, David. "El viaje a Europa". Literatura Argentina y realidad política: de Sarmiento a Cortázar. Buenos Aires: Ediciones Siglo Veinte, 1974. 